\title{
PERBANDINGAN MODEL KERUSAKAN TEGAKAN TINGGAL DI HUTAN ALAM DIPTEROCARP UNTUK MENDUKUNG MEKANISME REDD PLUS
}

\section{Comparison of Residual Stand Damage Models on Dipterocarp Forest to Support REDD Plus Mechanism}

\author{
Yonky Indrajaya \\ Balai Penelitian Teknologi Agroforestry \\ Jl. Raya Ciamis - Banjar KM.4 Ciamis, 46201, Indonesia \\ e-mail: yonky_indrajaya@yahoo.com
}

Diterima 16-12-2014, direvisi 07-10-2015, disetujui 29-10-2015

\begin{abstract}
ABSTRAK
Pembangunan model kerusakan tegakan tinggal akibat kegiatan pembalakan hutan alam dilakukan untuk mengetahui pengaruh pohon ditebang terhadap kerusakan yang terjadi. Beberapa model kerusakan tegakan tinggal antara lain: (1) kerusakan tetap dan tidak terpengaruh oleh jumlah pohon ditebang, (2) kerusakan tegakan tinggal dipengaruhi oleh jumlah pohon yang ditebang dengan proporsi kerusakan sama untuk semua kelas diameter, dan (3) matriks kerusakan, dimana proporsi kerusakan tegakan tinggal dipengaruhi oleh jumlah pohon ditebang dan berbeda tingkat kerusakannya untuk tiap kelas diameter. Tulisan ini bertujuan untuk menganalisis model-model kerusakan tegakan tinggal dan pengaruhnya terhadap pengelolaan hutan khususnya cadangan karbon hutan. Metode yang digunakan dalam penelitian ini adalah pembangunan model matriks kerusakan. Hasil yang diperoleh dari penelitian ini adalah: (1) model 1 memberikan hasil yang overestimate terhadap kerusakan yang terjadi pada teknik pembalakan CL, (2) model 2 memberikan hasil yang underestimate terhadap kerusakan tegakan tinggal pada teknik pembalakan konvensional (CL), dan (3) model 3 memberikan gambaran yang lebih nyata akan proporsi kerusakan yang terjadi akibat kegiatan pembalakan.
\end{abstract}

Kata kunci: model kerusakan, tegakan tinggal, pembalakan konvensional (CL), pembalakan berdampak rendah (RIL)

\section{ABSTRACT}

The development of harvest-damage model in natural production forest has been done to analyze the effect of harvesting activity on damage of residual stand. There are three models of damage on residual stand: (1) constant damage, independent from number of trees harvested, (2) dependent on number of trees harvested with the same damage on all diameter classes, and (3) damage matrix, which is dependent on number of trees harvested and consider different damage among diameter classes on residual stand. This paper aims to analyze the harvest-damage models and their effects on carbon dynamics. The method used in this study is damage matrix. The results of this study show that: (1) model 1 gives overestimate damage on residual stand under CL, (2) model 2 gives underestimate damage on residual stand under CL, and (3) model 3 gives more realistic feature of the proportion of damage as the effect of logging activity.

Keywords: damage model, residual stand, CL, RIL

\section{PENDAHULUAN}

Pembalakan hutan alam tropis dilakukan dengan menggunakan sistem silvikultur tebang pilih, yaitu menebang pohon komersial dengan batasan diameter tertentu (Kementerian Kehutanan, 2009). Konsekuensinya, pohon yang tidak ditebang berpotensi untuk menjadi rusak atau mati akibat kegiatan penebangan pohon komersial seperti tertimpa pohon rebah dan rusak karena dilalui jalan sarad. Introduksi teknik pembalakan berdampak rendah/Reduced Impact
Logging (RIL) dapat mengurangi kerusakan tegakan tinggal yang terjadi hingga 30\% (Putz et al., 2008). Penurunan kerusakan hutan dengan penerapan RIL merupakan salah satu strategi mitigasi perubahan iklim yaitu menurunkan laju degradasi hutan dalam mekanisme REDD (Reducing Emissions from Deforestation and forest Degradation) Plus.

Pendekatan model kerusakan tegakan tinggal telah dikembangkan di hutan tropis di dunia, antara lain: (1) kerusakan tetap dan independent 
terhadap jumlah pohon yang ditebang (Mendoza et al., 2000; Sasaki et al., 2012), (2) jumlah pohon yang ditebang akan mempengaruhi jumlah kerusakan yang terjadi (Sist et al., 2003; Martin et al., 2015), dan (3) matriks kerusakan tegakan tinggal (Boscolo and Vincent, 2000; Macpherson et al., 2010). Model kerusakan tegakan tinggal pertama berasumsi bahwa tingkat kerusakan tegakan yang terjadi bersifat tetap tidak tergantung pada jumlah pohon yang ditebang (Bertault and Sist, 1997; Sist et al., 1998). Model ini tentunya akan memiliki kelemahan yaitu tingkat kerusakan yang sama pada berbagai intensitas tebangan yang terjadi.

Model kerusakan tegakan tinggal ke-2 yang dikembangkan oleh Sistetal. (2003) hanyaberlaku untuk teknik pembalakan berdampak rendah (RIL), sedangkan dalam sistem pembalakan CL mengikuti hubungan yang dibuat oleh Picard et al. (2012). Model kerusakan ke-3 yang dibangun adalah model matriks yang mengasumsikan bahwa jumlah kerusakan tegakan yang terjadi tergantung dari jumlah pohon yang ditebang pada diameter tertentu (Boscolo and Buongiorno, 1997; Boscolo and Vincent, 2000). Makin besar pohon yang ditebang, makin tinggi tingkat kerusakan yang terjadi. Namun demikian, model tersebut mengasumsikan bahwa kerusakan yang timbul hanya pada pohon dengan diameter kecil saja. Model matriks yang dikembangkan oleh Macpherson et al. (2010) merupakan model yang mempertimbangkan kerusakan yang terjadi pada semua kelas diameter berdasarkan jumlah pohon dengan diameter tertentu.

Penggunaan model kerusakan tegakan tinggal yang berbeda berpotensi untuk memberikan hasil estimasi dinamika karbon hutan yang berbeda pula. Esimasi dinamika karbon tersimpan dalam biomassa hutan alam yang dikelola dengan menggunakan sistem silvikultur tebang pilih penting untuk mendukung mekanisme REDD+. Implementasi RIL dalam kerangka pengelolaan hutan lestari/Sustainable Forest Management (SFM) merupakan salah satu strategi mitigasi perubahan iklim sektor kehutanan (VCS, 2013). Sementara itu, model penduga kerusakan tegakan tinggal yang ada cukup beragam. Oleh karena itu, pemilihan model yang tepat dapat memberikan hasil estimasi yang paling mendekati kenyataan. Tulisan ini bertujuan untuk membandingkan beberapa model kerusakan tegakan tinggal yang ada dan pengaruhnya terhadap cadangan karbon hutan.

\section{METODELOGI PENELITIAN}

\section{A. Model Pertumbuhan Hutan}

Model pertumbuhan matriks transisi digunakan untuk mengetahui dinamika karbon tersimpan dalam biomassa hutan alam akibat kegiatan pembalakan. Model ini telah banyak digunakan di hutan dipterocarp (Mendoza and Setyarso, 1986; Vanclay, 1994; Boscolo and Vincent, 2000; Mendoza et al., 2000; Krisnawati et al., 2008). Model matriks transisi yang digunakan dalam penelitian ini adalah model yang dibangun oleh Krisnawati et al. (2008). Deskipsi dari model matriks transisi tersebut (Krisnawati et al., 2008) dijelaskan dalam paragraf berikut.

Pada waktu $t$ suatu tegakan hutan direpresentasikan oleh vector $\mathbf{y}_{t}=\left[y_{i j t}\right]$, dimana $y_{i j}$ merupakan jumlah pohon per ha dari kelompok jenis $i \in\{1, . ., m\}$ dan kelas diameter $j \in\{1, . ., n\}$ . Jumlah pohon yang ditebang direpresentasikan oleh vector $\mathbf{h}_{t}=\left[h_{i j t}\right]$. Karena adanya kegiatan pembalakan dengan teknik $s$, dimana terdapat dua teknik pembalakan yaitu konvensional (CL) dan berdampak rendah (RIL), maka jumlah pohon yang mati pada waktu $t$ akibat penebangan pohon sebanyak $h$ direpresentasikan dalam vector $\mathbf{d}_{s t}$. Jumlah pohon pada waktu $t+\theta$ merupakan perkalian antara matriks $\mathbf{G}$ (matriks pertumbuhan) dengan jumlah tegakan tinggal, yang disajikan dalam Persamaan (1):

$\mathbf{y}_{t+\theta}=\mathbf{G}\left(\mathbf{y}_{t}-\mathbf{h}_{t}-\mathbf{d}_{t}\right)+\mathbf{c}$

\section{B. Model Kerusakan Tegakan Tinggal}

Model kerusakan tegakan tinggal yang dibandingkan dalam penelitian ini adalah: (1) model kerusakan tetap dan sama untuk semua kelas diameter, $\mathbf{d}_{s, t}=d_{s} \mathbf{y}_{t}$ dimana $d$ adalah persentase kerusakan tegakan tinggal; (2) 
kerusakan tergantung pada jumlah pohon yang ditebang dan sama untuk semua kelas diameter, $\mathbf{d}_{s, t}=d_{s} \mathbf{y}_{t}$, dimana $d$ merupakan persentase kerusakan tegakan tinggal yang ditentukan oleh banyaknya pohon yang ditebang $h$ dengan persamaan $d_{s}=\delta h+\varepsilon$ dan $\delta$ dan $\varepsilon$ merupakan konstanta. Selain itu, $d$ dapat pula memiliki hubungan dengan $h$ sebagai berikut: $d_{s}=1-\frac{1}{(1+\psi h)^{\omega}}$, dimana $\psi$ dan $\omega$ merupakan $A G B=\rho \times \exp \left(-1.499+2.148 \ln (D)+0.207(\ln (D))^{2}-0.028(\ln (D))^{3}\right.$

Dimana AGB merupakan berat biomassa di atas permukaan tanah (kg/pohon), $\rho$ merupakan berat jenis kayu $(\mathrm{gr} / \mathrm{cm} 3)$, dan $D$ merupakan diameter setinggi dada $(\mathrm{cm})$. Dalam perhitungan nilai $D$ yang digunakan dalam penelitian adalah nilai tengah dari tiap kelas diameter $j$. Berat jenis kayu yang digunakan adalah 0,6 (Rahayu et al., 2006). Jumlah karbon tersimpan dalam biomassa adalah sebesar 0,47 dari berat biomassanya (IPCC, 2006). Berat karbon pada tiap kelompok jenis $i$ dan kelas diameter $j$ disajikan dalam vektor $\chi$, yang secara rinci disajikan dalam Lampiran 1 . Jumlah karbon tersimpan dalam biomassa hutan pada tahun $t$ dihitung dengan persamaan berikut:

$$
C_{t}=\chi^{\prime} \mathbf{y}_{t}
$$

Nilai rata-rata karbon tersimpan dalam satu daur adalah:

$$
\bar{C}=\frac{1}{\gamma} \sum_{t=0}^{T} \chi^{\prime} \mathbf{y}_{t}
$$

Dimana $\gamma$ merupakan jumlah dari $\theta$ (periode pertumbuhan), dan $T$ adalah daur.

\section{Pengelolaan Hutan}

Pengelolaan hutan alam dipterocarp dilakukan dengan sistem silvikultur tebang pilih. Daur tebangan yang digunakan dalam penelitian ini adalah 30 tahun dengan batas minimal diameter yang dapat ditebang adalah $40 \mathrm{~cm}$ sesuai dengan peraturan TPTI (Kementerian Kehutanan, 2009). Intensitas tebangan yang digunakan adalah intensitas sedang ( 8 pohon per konstanta; (3) model matriks kerusakan hutan, $\mathbf{d}_{s t}=h \mathbf{D}_{s} \mathbf{y}_{t}$, dimana matriks $\mathbf{D}_{s}$ merupakan matriks $m n \times m n$ dan diagonal matriks tersebut berisi koefisien kerusakan dari tiap kelompok jenis $i$ dan kelas diameter $j$ pada teknik pembalakan $s$.

\section{Perhitungan Cadangan Karbon dalam Biomassa}

Estimasi berat biomassa di atas permukaan tanah menggunakan persamaan alometrik yang dibangun oleh Chave et al. (2005), yaitu:

ha), sedangkan teknik pembalakan yang dilakukan adalah konvensional (CL) dan berdampak rendah (RIL).

\section{HASIL DAN PEMBAHASAN}

\section{A. Model 1: Kerusakan tetap dan sama untuk semua kelas diameter dan pengaruhnya terhadap dinamika cadangan karbon hutan}

Beberapa penelitian mengasumsikan adanya kerusakan tegakan yang tetap dan tidak terpengaruh jumlah pohon yang ditebang. Mendoza et al. (2000) dalam penelitiannya di Kalimantan mengasumsikan bahwa kerusakan tegakan tinggal adalah sebesar 20\% dan 30\% dari total pohon yang ada. Selain itu, Sist and Saridan (1998) menemukan bahwa kerusakan tegakan tinggal dengan menggunakan teknik penebangan konvensional dan pembalakan berdampak rendah berturut-turut adalah sebesar $46,2 \%$ dan $26,2 \%$. Pada model ini tingkat kerusakan yang terjadi sama untuk semua kelas diameter dan tidak terpengaruh oleh jumlah pohon yang ditebang. Selain itu, tingkat kerusakan tegakan tinggal pada CL juga dilaporkan sebesar antara 46-56\% (Sist et al., 2003), 48\% (Sist et al., 1998), sedangkan tingkat kerusakan tegakan tinggal pada RIL dilaporkan sebesar 25-30\% (Bertault and Sist, 1997; Sist et al., 1998). Berdasarkan beberapa penelitian di atas, penelitian dapat menggunakan tingkat kerusakan sebesar 48\% untuk CL dan 26\% untuk RIL. Hasil simulasi dinamika cadangan karbon hutan yang dikelola dengan teknik pemanenan CL dan RIL dengan model kerusakan ini disajikan pada Gambar 1. 


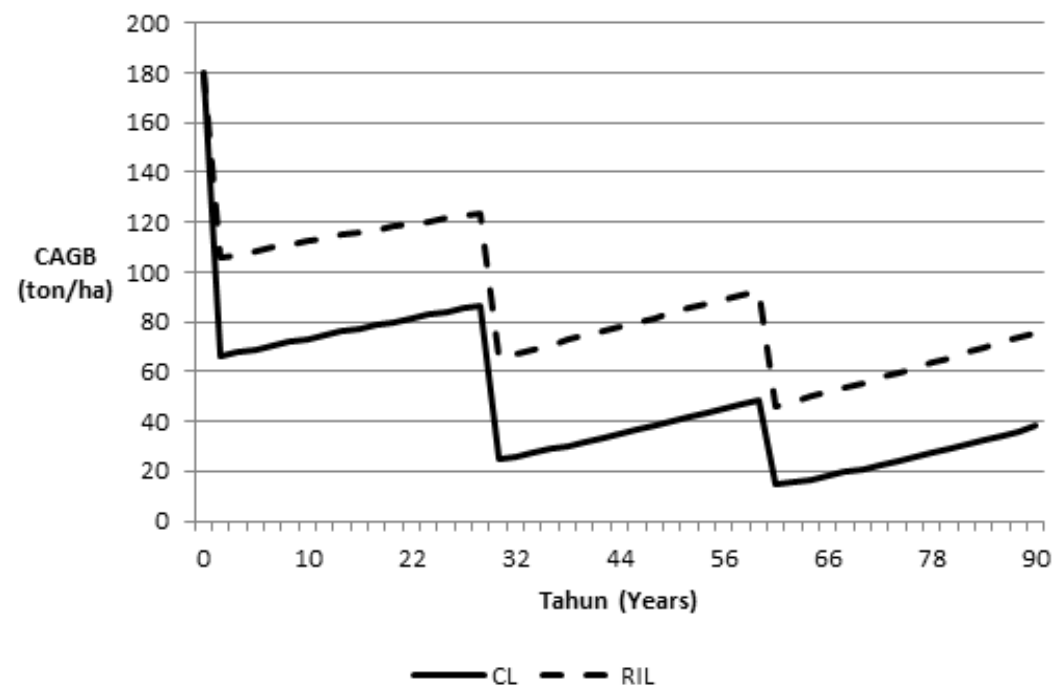

Gambar 1. Dinamika karbon hutan teknik pembalakan CL dan RIL dengan model kerusakan 1 Figure 1. Carbon dynamics of forest under CL and RIL with damage model 1

Sumber: diolah dari data primer

Gambar 1 menunjukkan adanya perbedaan yang cukup tinggi antara cadangan karbon hutan yang dikelola dengan teknik pembalakan CL dan RIL pada semua daur. Persentase kerusakan yang sifatnya tetap dan independent terhadap jumlah pohon yang ditebang pada model 1 dengan perbedaan yang cukup tinggi antara keduanya $(\mathrm{CL} 26 \%$ dan $\mathrm{RIL}=48 \%$ ) menyebabkan perbedaan cadangan karbon yang cukup tinggi antara keduanya.

B. Model 2: kerusakan tergantung pada jumlah pohon ditebang dan sama untuk semua kelas diameter meter dan pengaruhnya terhadap dinamika cadangan karbon hutan
Jumlah pohon yang rusak atau mati akibat kegiatan pembalakan dengan teknik $s$ yaitu $\mathbf{d}_{s, t}=d_{s} \mathbf{y}_{t}$. Persentase kerusakan yang terjadi pada tegakan tinggal $d$ yang dikelola dengan teknik pembalakan CL telah ditemukan oleh Picard et al. (2012) yaitu:

$d_{C L}=1-\frac{1}{(1+0.09135 h)^{0.70461}} \operatorname{dimana} h$

merupakan jumlah pohon yang ditebang. Sementara itu, pada teknik pembalakan RIL, hubungan linier ditemukan oleh Sist et al. (2003), yaitu $d_{R I L}=0.0454 h+0.0388$. Pada model 2 tingkat kerusakan yang ada diasumsikan sama untuk semua kelas diameter.

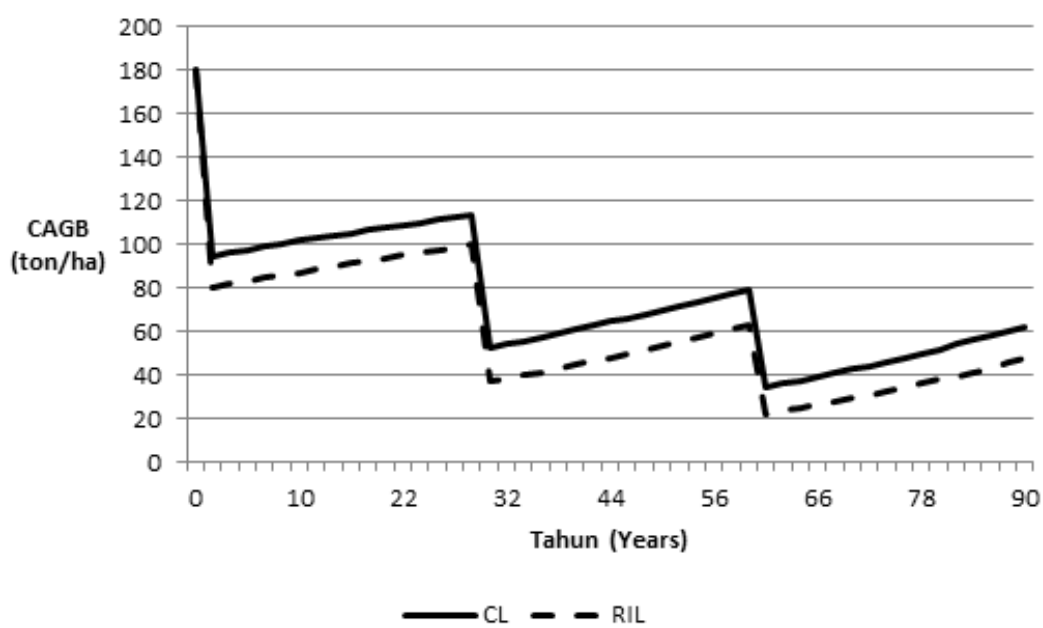

Gambar 2. Dinamika karbon hutan teknik pembalakan CL dan RIL dengan model kerusakan 2

Figure 2. Carbon dynamics of forest under CL and RIL with damage model 2 
Gambar 2 menunjukkan jumlah karbon tersimpan dengan teknik pembalakan CL lebih tinggi dibandingkan RIL. Hal ini terjadi karena pada intensitas tebangan sedang (8 pohon per ha), estimasi kerusakan tegakan tinggal dalam teknik pembalakan CL dan RIL berturut-turut adalah sebesar $32 \%$ dan $40 \%$, sehingga karbon tersimpan dalam biomassa hutan CL menjadi lebih tinggi.

\section{Model 3: Model Matriks Kerusakan Hutan dan Pengaruhnya Terhadap Dinamika Cadangan Karbon Hutan}

Model ini dibangun dengan asumsi bahwa kerusakan yang terjadi pada tegakan tinggal akibat penebangan satu pohon akan berbeda pada tiap kelas diameter tegakan tinggal. Kelas diameter yang lebih tinggi akan memiliki kekuatan yang lebih tinggi apabila tertimpa pohon yang ditebang, sehingga kerusakan yang terjadi relatif lebih kecil dibandingkan dengan kelas diameter yang lebih kecil.

Macpherson et al. (2010) menyebutkan bahwa hubungan jumlah pohon ditebang dengan tingkat kerusakan tegakan tinggal menggunakan persamaan: $\mathbf{d}_{s t}=h \mathbf{D}_{s} \mathbf{y}_{t}$, dimana $\mathbf{d}_{s t}$ merupakan vector kerusakan berisi $d_{s t}$ jumlah pohon yang mati akibat pohon yang ditebang sebanyak $h$. $\mathbf{D}_{s}$ merupakan matriks $m n \times m n$ dimana diagonal matriks tersebut berisi koefisien kerusakan dari tiap kelompok jenis $i$ dan kelas diameter $j$ pada teknik penebangan s. Pembangunan model ini telah dilakukan oleh Indrajaya et al. (2014) berdasarkan data CIFOR (Priyadi et al., 2007) di Kalimantan Timur pada teknik pembalakan CL dan RIL. Hasil simulasi dinamika karbon hutan dengan teknik pembalakan CL dan RIL menggunakan model ini disajikan dalam Gambar 3.

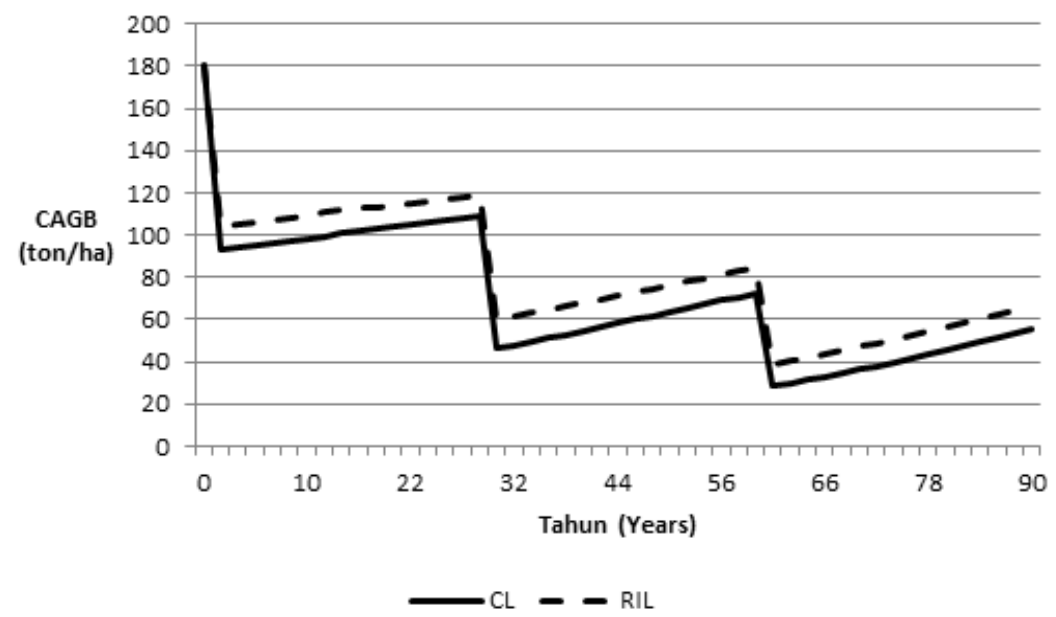

Gambar 3. Dinamika karbon hutan teknik pembalakan CL dan RIL dengan model kerusakan 3 Figure 3. Carbon dynamics of forest under CL and RIL with damage model 3

Sumber: diolah dari data primer

Gambar 3 menunjukkan perbedaan yang tidak terlalu tinggi antara karbon tersimpan dalam biomassa hutan dengan teknik pembalakan CL dan RIL. Karbon tersimpan dalam biomassa hutan dengan teknik pembalakan RIL lebih tinggi dibandingkan CL. Model ini memberikan gambaran yang lebih nyata tentang pengaruh jumlah pohon ditebang dengan jumlah kerusakan yang terjadi.

\section{Perbandingan Hasil Beberapa Model} Kerusakan Tegakan Tinggal Terhadap Karbon Tersimpan dalam Biomassa di Atas Permukaan Tanah

Dalam rangka mengurangi emisi karbon yang berkontribusi terhadap perubahan iklim, pengurangan laju degradasi hutan merupakan salah satu langkah mitigasi yang dapat dilakukan (Murdiyarso et al., 2008). Perhitungan karbon 
tersimpan dalam biomassa hutan terkait dengan manajemen pengelolaan hutan yang dilakukan menjadi perlu untuk dilakukan. Perhitungan potensi karbon tersimpan dalam teknik pembalakan CL dan RIL telah dilakukan (Putz et al., 2008; Sasaki et al., 2012). Penerapan RIL berpotensi untuk mengurangi emisi karbon dan telah diakui sebagai salah satu aktivitas mitigasi perubahan iklim (Dangerfield et al., 2013). Perhitungan additionality dalam proyek karbon terkait penerapan RIL untuk mitigasi perubahan iklim memperhitungkan perbedaan rata-rata karbon tersimpan dalam RIL (dengan proyek) dan CL (tanpa proyek) (VCS, 2013). Oleh karena itu, perhitungan rata-rata karbon tersimpan dalam tiap daur menjadi relevan untuk dilakukan. Hasil perhitungan rata-rata karbon tersimpan dalam biomassa hutan yang dikelola dengan teknik pembalakan CL dan RIL pada beberapa model kerusakan tegakan tinggal dalam tiap daur disajikan pada Tabel 1.

Tabel 1. Rata-rata karbon tersimpan dalam biomassa hutan dengan teknik pembalakan CL dan RIL pada beberapa model kerusakan tegakan tinggal (dalam ton/ha)

Table 1. Average C-stock in the forest under logging techniques of CL and RIL under different residual stand damage models (in ton/ha)

\begin{tabular}{|c|c|c|c|c|}
\hline \multirow{2}{*}{$\begin{array}{l}\text { Sistem pemanenan dan model } \\
\text { kerusakan } \\
\text { (harvesting system and damage } \\
\text { model) }\end{array}$} & \multirow{2}{*}{$\begin{array}{l}\text { Karbon sebelum } \\
\text { tebangan } \\
\text { (C before harvest })\end{array}$} & \multicolumn{3}{|c|}{$\begin{array}{l}\text { Rata-rata karbon tersimpan } \\
\text { (Time average C-stock in one cutting cycle) }\end{array}$} \\
\hline & & $\begin{array}{l}\text { Daur } \\
\text { (cutting cyle) } 1\end{array}$ & $\begin{array}{l}\text { Daur } \\
\text { (cutting cyle) } 2\end{array}$ & $\begin{array}{l}\text { Daur } \\
\text { (cutting cyle) } 3\end{array}$ \\
\hline CL Model 1 & 180 & 77 & 36 & 25 \\
\hline RIL Model 1 & 180 & 115 & 79 & 61 \\
\hline CL Model 2 & 180 & 104 & 65 & 47 \\
\hline RIL Model 2 & 180 & 90 & 49 & 34 \\
\hline CL Model 3 & 180 & 101 & 59 & 41 \\
\hline RIL Model 3 & 180 & 112 & 72 & 52 \\
\hline
\end{tabular}

Sumber: diolah dari data primer

Tabel 1 menunjukkan bahwa dengan intensitas penebangan sedang ( 8 pohon per ha), pada daur ke-3 terjadi penurunan rata-rata karbon tersimpan dalam biomassa hutan pada semua teknik pembalakan dengan semua model kerusakan tegakan tinggal. Model 1 memberikan hasil yang sangat berbeda dalam rata-rata karbon tersimpan dalam biomassa tiap daur antara CL dan RIL. Apabila dibandingkan dengan hasil dari model lain, karbon tersimpan dalam biomassa hutan dengan teknik pembalakan CL menghasilkan nilai terendah dengan perbedaan yang cukup tinggi pada daur pertama (77 vs 104 dan 101). Hal ini menunjukkan bahwa model kerusakan tegakan tinggal dengan teknik pembalakan CL memberikan hasil yang overestimate. Sementara itu, model 2 menghasilkan nilai rata-rata karbon tersimpan dalam biomassa dengan teknik pembalakan CL yang lebih tinggi dari RIL, atau estimasi kerusakan tegakan tinggal yang terjadi dengan model ini underestimate.

Kekurangan dari model 1 adalah dengan kerusakan yang diasumsikan tetap, maka pada kasus tidak ada penebangan, maka tetap akan terjadi kerusakan pada tegakan tinggal, dan kerusakan yang terjadi sama untuk semua intensitas tebangan. Sementara itu, pada model 2 kerusakan yang terjadi diasumsikan sama untuk semua kelas diameter. Padahal pohon berdiameter besar tentunya akan memiliki kekuatan yang lebih besar dibandingkan pohon dengan diameter kecil sehingga, seharusnya kerusakan yang terjadi relatif lebih kecil pada diameter yang lebih besar. Model 3 diduga akan memberikan gambaran yang lebih nyata akan proporsi kerusakan yang terjadi akibat kegiatan pembalakan, karena model 3 telah mempertimbangkan kerusakan yang terjadi berdasarkan jumlah pohon yang ditebang dan proporsi kerusakan antar kelas diameter. 


\section{KESIMPULAN DAN SARAN}

\section{A. Kesimpulan}

Berdasarkan hasil dan pembahasan di atas, dapat ditarik kesimpulan:

1. Model 1 memberikan hasil yang overestimate terhadap kerusakan yang terjadi pada teknik pembalakan konvensional (CL), sehingga rata-rata karbon tersimpan dalam biomassa dengan teknik pembalakan CL menjadi sangat rendah dibandingkan dengan RIL.

2. Model 2 memberikan hasil yang underestimate terhadap kerusakan tegakan tinggal yang terjadi pada teknik pembalakan konvensional (CL), sehingga rata-rata karbon tersimpan dalam biomassa dengan teknik pembalakan CL menjadi lebih tinggi dari RIL.

3. Model 3 diduga akan memberikan gambaran yang lebih nyata akan proporsi kerusakan yang terjadi akibat kegiatan pembalakan.

\section{B. Saran}

Penelitian ini menunjukkan bahwa model kerusakan tegakan tinggal cukup penting dalam estimasi jumlah karbon tersimpan dalam biomassa di atas permukaan tanah hutan yang dikelola dengan tebang pilih. Perlu penelitian lebih lanjut apabila pool karbon lain seperti biomassa mati, akar, dan produk kayu diperhitungkan dalam analisis sehingga memberikan hasil yang lebih baik.

\section{DAFTAR PUSTAKA}

Bertault, J.G., Sist, P., (1997). An experimental comparison of different harvesting intensities with reduced-impact and conventional logging in East Kalimantan, Indonesia. Forest Ecol Manag 94, 209-218.

Boscolo, M., Buongiorno, J., (1997). Managing a tropical rainforest for timber, carbon storage and tree diversity. Commonwealth Forestry Review 76, 246-254.

Boscolo, M., Vincent, J.R., (2000). Promoting better logging practices in tropical forests: a simulation analysis of alternative regulations. Land Economics 76, 1-14.

Chave, J., Andalo, C., Brown, S., Cairns, M.A., Chambers, J.Q., Eamus, D., Folster, H., Fromard, F., Higuchi, N., Kira, T., Lescure, J.P., Nelson, B.W., Ogawa, H., Puig, H., Riera,
B., Yamakura, T., 2005. Tree allometry and improved estimation of carbon stocks and balance in tropical forests. Oecologia 145, 8799.

Dangerfield, M., Wilson, C., Pearson, T., Schultz, J., (2013). Methodology for Improved Forest Management: Conversion from Logged to Protected Forest. Approved VCS Methodology VM 0010, Version 1.2.

Indrajaya, Y., van der Werf, E., van Ierland, E., Mohren, F., (2014). Optimal forest management when logging damages and costs differ between logging practices. In, CESifo Working Papers No 4606.

IPCC, (2006). IPCC Guideline 2006 Guidelines for national green house gas inventories. In. IPCC.

Kementerian Kehutanan, (2009). Peraturan Menteri Kehutanan Nomor: P.11/Menhut-II/2009 tentang Sistem silvikultur dalam areal izin usaha pemanfaatan hasil hutan kayu pada hutan produksi. In. Kementerian Kehutanan, Jakarta.

Krisnawati, H., Suhendang, E., Parthama, I.P., (2008). Transition matrix growth models for logged over natural forest in Central Kalimantan. Jurnal Penelitian Hutan dan Konservasi Alam 5, 107-128.

Macpherson, A.J., Schulze, M.D., Carter, D.R., Vidal, E., (2010). A Model for comparing reduced impact logging with conventional logging for an Eastern Amazonian Forest. Forest Ecol Manag 260, 2002-2011.

Martin, P.A., Newton, A.C., Pfeifer, M., Khoo, M., Bullock, J.M., (2015). Impacts of tropical selective logging on carbon storage and tree species richness: A meta-analysis. Forest Ecol Manag.

Mendoza, G.A., Onal, H., Soetjipto, W., (2000). Optimising tree diversity and economc returns from managed mixed forest in Kalimantan, Indonesia. Journal of Tropical Forest Science 12, 298-319.

Mendoza, G.A., Setyarso, A., (1986). A transition matrix forest growth-model for evaluating alternative harvesting schemes in Indonesia. Forest Ecol Manag 15, 219-228.

Murdiyarso, D., Skutsh, M., Guariguata, M., Kanninen, M., Luttrell, C., Verweij, P., Martins, O.S., (2008). How do we measure and monitor forest degradation. In: Angelsen, A. (Ed.), Moving ahead with REDD: Issues, options, and implications. CIFOR, Bogor Indonesia.

Picard, N., Gourlet-Fleury, S., Forni, E., (2012). Estimating damage from selective logging and implications for tropical forest management. Can J Forest Res 42, 605-613.

Priyadi, H., Sist, P., Gunarso, P., Kanninen, M., Kartawinata, K., Sheil, D., Setyawati, T., Dwiprabowo, H., Siswoyo, H., Silooy, G., 
Siregar, C.A., Dharmawan, W.S., (2007). Reduced Impact Logging: Benefits and Constraints. In: Gunarso, P., Setyawati, T., Sunderland, T., Shackleton, C. (Eds.), Managing Forest Resources in A Decentralized Environment: Lessons learnt from the Malinau Forest, East Kalimantan, Indonesia. CIFOR, Bogor Indonesia.

Putz, F.E., Zuidema, P.A., Pinard, M.A., Boot, R.G.A., Sayer, J.A., Sheil, D., Sist, P., Elias, Vanclay, J.K., (2008). Improved tropical forest management for carbon retention. Plos Biol 6, 1368-1369.

Rahayu, S., Lusiana, B., Noordwijk, M.v., (2006). Pendugaan cadangan karbon di atas permukaan tanah pada berbagai sistem penggunaan lahan di Kabupaten Nunukan, Kalimantan Timur. In: Lusiana, B., Noordwijk, M.v., Rahayu, S. (Eds.), Cadangan karbon di Kabupaten Nunukan, Kalimantan Timur: monitoring secara spasial dan pemodelan. Laporan tim proyek pengelolaan sumberdaya alam untuk penyimpanan karbon (formacs). World Agroforestry Center, Bogor Indonesia.
Sasaki, N., Chheng, K., Ty, S., (2012). Managing production forests for timber production and carbon emission reductions under the REDD+ scheme. Environ Sci Policy 23, 35-44.

Sist, P., Nolan, T., Bertault, J.G., Dykstra, D., (1998). Harvesting intensity versus sustainability in Indonesia. Forest Ecol Manag 108, 251-260.

Sist, P., Saridan, A., (1998). Description of the primary lowland forest of Berau. Silvicultural research in a lowland mixed dipterocarp forest of East Kalimantan, the contribution of STREK project., Jakarta.

Sist, P., Sheil, D., Kartawinata, K., Priyadi, H., (2003). Reduced-impact logging in Indonesian Borneo: some results confirming the need for new silvicultural prescriptions. Forest Ecol Manag 179, 415-427.

Vanclay, J.K., (1994). Modelling forest growth and yield: applications to mixed tropical forests. CAB International.

VCS, (2013). Agriculture, Forestry and Other Land Use (AFOLU) Requirements. In. Verified Carbon Standard. 
Lampiran 1. Prediksi biomassa di atas permukaan tanah, biomassa akar, dan karbon tersimpan dalam biomassa jenis diperocarp, non dipterocarp dan non komersial

Appendix 1. Predicted above ground biomass, root biomass, and carbon stored in biomass in dipterocarp, nondipterocarp and non-commercial species

\begin{tabular}{ccccccc}
\hline \multirow{2}{*}{$\begin{array}{c}\text { Diameter (Diameter) } \\
(\mathrm{cm})\end{array}$} & \multicolumn{2}{c}{ Dipterocarp } & \multicolumn{2}{c}{ Non Dipterocarp } & \multicolumn{2}{c}{ Non-commercial } \\
\cline { 2 - 7 } & $\begin{array}{c}\text { AGB } \\
\text { (ton /tree) }\end{array}$ & $\begin{array}{c}\text { C stock } \\
\text { (ton /tree) }\end{array}$ & $\begin{array}{c}\text { AGB } \\
\text { (ton /tree) }\end{array}$ & $\begin{array}{c}\text { C stock } \\
\text { (ton /tree) }\end{array}$ & $\begin{array}{c}\text { AGB } \\
\text { (ton /tree) }\end{array}$ & $\begin{array}{c}\text { C stock } \\
\text { (ton /tree) }\end{array}$ \\
\hline $10-14$ & 0.082 & 0.039 & 0.082 & 0.039 & 0.082 & 0.039 \\
\hline $15-19$ & 0.200 & 0.094 & 0.200 & 0.094 & 0.200 & 0.094 \\
\hline $20-24$ & 0.388 & 0.183 & 0.388 & 0.183 & 0.388 & 0.183 \\
\hline $25-29$ & 0.655 & 0.308 & 0.655 & 0.308 & 0.655 & 0.308 \\
\hline $30-34$ & 1.009 & 0.474 & 1.009 & 0.474 & 1.009 & 0.474 \\
\hline $35-39$ & 1.454 & 0.683 & 1.454 & 0.683 & 1.454 & 0.683 \\
\hline $40-44$ & 1.995 & 0.938 & 1.995 & 0.938 & 1.995 & 0.938 \\
\hline $45-49$ & 2.636 & 1.239 & 2.636 & 1.239 & 2.636 & 1.239 \\
\hline $50-54$ & 3.378 & 1.587 & 3.378 & 1.587 & 3.378 & 1.587 \\
\hline $55-59$ & 4.222 & 1.984 & 4.222 & 1.984 & 4.222 & 1.984 \\
\hline $60-64$ & 5.171 & 2.430 & 5.171 & 2.430 & 5.171 & 2.430 \\
\hline $65-69$ & 6.223 & 2.925 & 6.223 & 2.925 & 6.223 & 2.925 \\
\hline$\geq 70$ & 7.380 & 3.469 & 7.380 & 3.469 & 7.380 & 3.469 \\
\hline
\end{tabular}

Sumber: diolah dari data primer 
JURNAL Penelitian Ekosistem Dipterokarpa Vol. 1 No. 2, Desember 2015 : 89 - 98 